\title{
Relationships of Urinary $\beta 2$ - microglobulin in Neonates with Impaired Renal Function in Different Stages of Hypoxic Ischaemic Encephalopathy
}

\author{
M BANERJEE ${ }^{1}$, SK MAJUMDAR ${ }^{2}$, MD. SHAHIDULLAH ${ }^{3}$
}

\begin{abstract}
Hypoxic Ischaemic Encephalopathy (HIE) is a sequelae of neonates suffering from severe perinatal asphyxia. It may also cause impaired renal function due to acute tubularnecrosis followed by elevation of urinary concentration of certain low molecular weight proteins like $\beta 2-$ microglobulin. This study was designed to evaluate the urinary $\beta 2$ - microglobulin level in neonates with HIE patients those who have impaired renal function.

This prospective case control study was carried out in the Neonatal unit of the department of Pediatrics and in the Labor ward of the department of Obstetrics and Gynecology Bangabandhu Sheik Mujib Medical University, Dhaka during the period

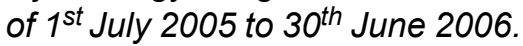

This study was designed to estimate urinary $\beta 2$ - micro globulin level in the asphyxiated newborn as well normal newborns to see any significant changes and to find out its relation with over all outcomes of newborns with perinatal asphyxia.

In this study, 42 term newborn babies before 24 hours of age, those who failed to take spontaneous breathing within 5 minutes of the complete delivery were taken as cases and 40 healthy term newborns were taken as control. Asphyxiated newborns were divided into three groups depending on the sarnat and sarnat clinical staging of HIE.

\begin{abstract}
Mean $\pm S D$ value of urinary $\beta$-2- micro globulin in case group $4.1 \pm 2.79 \mathrm{mg} / \mathrm{l}$ and in the control was $1.35 \pm 1.08 \mathrm{mg} / \mathrm{l}$. It shows significant $(p<0.01)$ rise of urinary $\beta$-2 micro globulin levels in case group. The degree of rise of urinary $\beta$-2- micro globulin was related with the severity of HIE but blood urea and serum creatinine levels were not increased significantly in stage I and stage II except in stage III HIE patients.

It was concluded from this study that raised urinary $\beta 2-$ microglobulin level may be related with HIE patients irrespective of clinical staging but serum creatinine and blood urea were found to be elevated only in stage III HIE patients. But to draw a conclusive evidence regarding relationship of urinary $\beta 2$ microglobulin with advance stages of HIE in neonates with impaired renal function require further large scale study.
\end{abstract}

Key Words: uninary $\beta$-2-microglobulin, perinatal asphyxia, Hypoxic/schaemic Encephalopathy

Introduction

Perinatal asphyxia is an insult to the fetus or newborn due to lack of oxygen (hypoxia) and/or a lack of perfusion (ischemia) to various organs ${ }^{1}$. Perinatal asphyxia can be defined as a condition of impaired blood gas exchange during the intrapartum period that leads to progressive hypoxemia and hypercapnea with metabolic acidosis ${ }^{2}$.

1. Associate Prof. Dept. of Neonatology, Dhaka Medical College, Dhaka.

2. Associate Prof. Dept. of Paediatric Surgery, Shaheed Suhrawardy Medical College, Dhaka.

3. Prof. and head Division of Neonatology, BSMMU, Dhaka.

Correspondence: Dr. M Banerjee, Associate Prof. Dept. of Neonatology, Dhaka Medical College. Dhaka.
In Bangladesh, approximately 40 lacks babies are born every year ${ }^{3}$. Almost $73 \%$ of these babies are delivered at home, mostly by unskilled attendants. Sixty percent $(60 \%)$ of all infant deaths occur during this neonatal period ${ }^{3}$.

The neonatal mortality rate (NMR) in Bangladesh is 37 per thousand live births ${ }^{4}$. Perinatal asphyxia is a major cause of morbidity and mortality among the newborns in the developing countries, including Bangladesh ${ }^{3}$. Although exact disease profile among the newborns is not known in Bangladesh, but hospital based study showed that neonatal death due to birth asphyxia is $28 \%$ in Bangladesh ${ }^{5}$. Assessment of renal 
function is very much important in perinatal asphyxia to reduce overall mortality and morbidity as perinatal asphyxia can lead to both acute and chronic renal failure. The incidence of Perinatal asphyxia is about 1 to $1.5 \%$ in most centers and is usually related to gestational age and birth weight. The incidence is higher in term infants of diabetic or toxemic mother ${ }^{1}$.

Usually for assessment of renal impairment in perinatal asphyxia, estimation of blood urea and serum creatinine is employed. But blood urea and serum creatinine levels rise only when glomerular filtration rate falls to a certain extent ${ }^{6}$. So they do not reflect the degree of renal injury in perinatal asphyxia because in asphyxia, glomerular injury dose not occur at least in the earlier state i.e. within 24 hours. In perinatal asphyxia, tubular cellular damage occurs due to acute tubular necrosis following hypoxic insult from asphyxia. For the early detection of tubular injury in asphyxia, markers of tubular dysfunction like urinary $\beta$-2- microglobulin would be better predictor than usual renal function tests ${ }^{7}$.

This study was designed to estimate urinary $\beta$-2microglobulin level in the asphyxiated newborn as well as in normal newborn to find out the level of urinary â2- microglobulin for early detection of renal injury and with over all out come of newborns with birth asphyxia.

\section{Methododology}

This prospective case-control study was carried out in the department of Neonatology and in the department of Obstetrics and Gynecology, Bangabandhu Sheikh Mujib Medical University (BSMMU), Dhaka, during the period of $1^{\text {st }}$ July 2005 to $30^{\text {th }}$ June 2006.

A total number of 82 consecutive newborns aged between $0-24 \mathrm{hrs}$ old were selected for the present study. Forty two (42) term neonates, apgar score $<6$ at 5 minutes with history of failure to breath spontaneously, evidence of asphyxia and history of resuscitation to sustain life after birth and evidence of development of hypoxic ischemic encephalopathy following birth, were taken as case (group-I) whereas 40 healthy term neonates, apgar score 8 or more at 5 minutes and free from any clinical evidence of renal disease and subtle cardiovascular system abnormality, apparently intact nervous system and no evidence of respiratory distress were enrolled in this study as control (group- II).

Exclusion criteria for both control and case group were newborn with congenital anomaly, evidence of sepsis or shock, having necrotizing enterocolities, respiratory distress syndrome, passed urine before enrollment and long history of nephrotoxic drug intake by mother, history of antepartum hemorrhage, shock or sepsis of mother, history of oligohydramnios of mother were excluded from this study.

All the asphyxiated neonates with clinical features of hypoxic ischemic encephalopathy (HIE) were staged according to Sarnat and Sarnat scoring system ${ }^{8}$.

Informed written consents from parents were obtained for each newborn before enrollment in this study. Permission was also taken from the concerned departmental ethical committee. After enrollment, relevant information's from history, physical findings and laboratory investigations were recorded on a predesigned questionnaire. All the study subjects were scrutinized by taking careful antenatal, natal and post natal history.

First voided urine was collected for estimation of urinary $\beta-2-$ microglobulin concentration. Blood was taken on day 3 to do blood urea and serum creatinine for renal function test. After enrollment urine collecting bag was applied over the external genitalia of each neonate for collection of first void urine. The full term healthy neonates (control) were studied in the obstetric wards and asphyxiated infants (case) were studied in the neonatology unit of BSMMU. During hospital stay all the asphyxiated babies were treated according to study protocol $\left(\mathrm{O}_{2}\right.$ inhalation, nasopharyngeal suction, intravenous fluid with parenteral antibiotics etc).

The data were entered into computer using SPSS for windows (version 10.2; SPSS inc., Chicago, IL, USA) and necessary data cleaing was done. Appropriate statistical analysis such as chi-square, unpaired 't' test were applied as necessity. P- value less than 0.05 was considered as significant.

\section{Results}

Among the 42 asphyxiated newborns of group II the common clinical presentations were central cyanosis (73.33\%), generalized convulsion (70\%), intolerance to feeding in the form of vomiting and increased gastric aspirate in nasogastric tube $(60 \%)$, hemorrhage in the form of gastrointestinal bleeding like haematemesis and maelena (33.33\%) and oliguria i.e. urine output of less than $1 \mathrm{ml} / \mathrm{kg} / \mathrm{hour}(33.33 \%)$. More than one clinical feature was present in most of the newborns. In each patient, Sarnat and Sarnat clinical staging of 
hypoxic ischemic encephalopathy (HIE) was done carefully. Twenty five $(25 \%)$ of the asphyxiated newborns were in stage I, $36.66 \%$ in stage II and $38.33 \%$ in stage III of HIE.

Mean value of urinary $\beta$-2 microglobulin in case group $4.1 \pm 2.79 \mathrm{mg} / \mathrm{l}$ and in the control was $1.35 \pm 1.08 \mathrm{mg} /$ I. It shows significant rise of $\beta-2$ microglobulin level in case group $(p<0.01)$.

In this study, it was found that urinary $\beta-2$ microglobulin was progressively raised from Stage-I HIE $(2.53 \pm 1.23)$ to Stage-III HIE $(5.22 \pm 1.16)$. The degree of rise of $\beta-2$ microglobulin consistent with the severity of HIE (Table II).

Table-III shows comparative study of mean values between blood urea and serum creatinine concentration in different stages of HIE in case group (group I) and in control (group II). Mean ( \pm SD) values of blood urea were $5.49 \pm 0.20,5.50 \pm 0.31$ and 5.90 $\pm 0.26 \mathrm{mmol} / \mathrm{L}$ in sarnat and sarnat HIE stage I, II and III, respectively and $5.02 \pm 0.22 \mathrm{mmol} / \mathrm{L}$ in control group.. The mean values of blood urea do not show significant differences between control group and different stages of HIE $(P<0.05)$ except stage III $(\mathrm{P}<0.01)$.

Mean $( \pm S D)$ values of serum creatinine were $78.44 \pm$ $8.27,78.53 \pm 12.55$ and $87.51 \pm 2.49 \mathrm{mmol} / \mathrm{l}$ in sarnat and sarnat HIE Stage I, II and III respectively and $44.32 \pm 6.71 \mathrm{mmol} / \mathrm{l}$ in contgrol group. No significant differences of mean values of serum creatinine between control and different stages of HIE were noted except in stage III $(P<0.01)$ patients.

In this study, progressive rise of urinary $\beta 2$ - micro globulin were showed rising tendency, depending on the severity of staging of HIE.

Table I

Urinary $\beta-2$ microglobulin level in case (Group I) and control (Group II) $(N=82)$.

\begin{tabular}{lc}
\hline Groups & $\begin{array}{c}\text { Urinary } \beta-2 \\
\text { microglobulin } \\
\text { mg/L(Mean } \pm S D)\end{array}$ \\
\hline Group-I $(n=42)$ & $4.10 \pm 2.79$ \\
Group-II $(n=40)$ & $1.35 \pm 1.08$ \\
P Value & $<0.01^{* *}$ \\
\hline
\end{tabular}

Significant differences between the two groups were calculated by unpaired Student's't' test, ${ }^{* *}=$ significant

\section{Table II}

Comparison of Urinary $\beta$-2 microglobulin level between case (Group I) and control (Group II) groups of the study subjects $(\mathrm{N}=82)$.

\begin{tabular}{lccc}
\hline Groups & \multicolumn{2}{c}{$\begin{array}{c}\text { Mean urinary } \beta-2 \\
\text { in different stages of HIE patients }\end{array}$} \\
\hline & HIE Stage-I & HIE Stage-II & HIE Stage-III \\
Group-I $(\mathrm{n}=42)$ & $2.53 \pm 1.23$ & $3.99 \pm 1.43$ & $5.22 \pm 1.16$ \\
Group-II $(\mathrm{n}=40)$ & $1.35 \pm 1.08$ & \\
\hline $\mathrm{P}$ Value & $<0.001^{* * *}$ & $<0.001^{* * *}$ & $<0.001^{* * *}$ \\
\hline
\end{tabular}

Significance of differences between the groups were calculated by unpaired Student's't' test, $* * *=$ significant

Table III

Comparison of renal function status between case and control groups of the study subjects.

\begin{tabular}{lccc}
\hline Parameters & \multicolumn{3}{c}{ Different stages of HIE patients } \\
& HIE Stage-I & HIE Stage-II & HIE Stage-III \\
\hline Blood Urea & & & \\
Group-I $(n=42)$ & $5.49 \pm 0.20$ & $5.50 \pm 0.31$ & $5.90 \pm 0.26$ \\
Group-II $(n=40)$ & $5.02 \pm 0.22$ & \\
P Value & $>0.05^{\mathrm{ns}}$ & $<0.05^{\mathrm{ns}}$ & $<0.01^{* *}$ \\
S. Creatinine & & & \\
Group-I $(\mathrm{n}=42)$ & $78.44 \pm 8.27$ & $78.53 \pm 12.55$ & $87.51 \pm 2.59$ \\
Group-II $(\mathrm{n}=40)$ & & $77.32 \pm 8.27$ & \\
P Value & $<0.05^{\mathrm{ns}}$ & $<0.05^{\mathrm{ns}}$ & $<0.01^{* *}$ \\
\hline
\end{tabular}

Significance of differences between the groups were calculated by unpaired Student's't' test, ${ }^{* * *}=$ significant, NS $=$ Not Significant

\section{Discussion}

Perinatal asphyxia can result in multi system organ damage in a neonate ${ }^{8}$. The kidney is very sensitive to oxygen deprivation. A less severe alteration in perfusion will result in more subtle injury of renal tubule. Such subtle injury can be detected by the urinary concentration of $\beta-2$ microglobulin within hours ${ }^{9}$. Injury to the proximal tubule results in markedly elevated concentration of $\beta-2$ microglobulin in the urine. Thus, measurement of urinary levels of this protein provides a sensitive indicator of proximal tubular function ${ }^{10}$. 
Urinary $\beta$-2 microglobulin concentration in healthy neonates averaged $1.34 \pm 1.34 \mathrm{mg} / \mathrm{l}$ (mean $\pm \mathrm{SD}$ ) in first voided specimens. The upper normal limit of urinary $\beta-2$ microglobulin is $4 \mathrm{mg} / \mathrm{I}^{10}$. In this study, among the asphyxiated group, the mean ( $\pm S D$ ) of $\beta-2$ microglobulin in urine was $5.22 \pm 1.16 \mathrm{mg} / \mathrm{l}$ in Sarnat stage III. Similar observation was made by other investigators $^{10}$.

In this study, we found statistically significant elevation of $\beta-2$ microglobulin in the urine of asphyxiated neonates compared to controls $(P<0.01)$ (Table II). Similar findings were observed by other worker in abroad ${ }^{11}$. So, estimation of urinary $\beta-2$ microglobulin in urine of asphyxiated newborns may be an indicator about the degree of renal impairment, which will guide to fluid and electrolyte management. In this study, we found an increasing activity of urinary $\beta-2$ microglobulin level in respect to degree of encephalopathy as determined by Sarnat staging (Table II). So, it further indicates that urinary $\beta-2$ microglobulin is a good indicator than usual renal function test to predict organ damaging effect of perinatal asphyxia. Some researcher found that â-2 microglobulin was the most sensitive indicator of systemic organ injury in perinatal asphyxia ${ }^{12}$. Other also confirmed this and suggested that $\beta-2$ microglobulin is more sensitive than usual renal function test in perinatal asphyxia ${ }^{11}$.

In our study, $65 \%$ asphyxiated newborns survived, $26.67 \%$ died, while $8.33 \%$ were discharged on risk bond (DORB). In this study, the rate of mortality from perinatal asphyxia correlates with other study in our country ${ }^{13}$, while other studies show mortality rate in asphyxiated newborns are $31.5 \%{ }^{9}$, and $25 \%{ }^{14}$.

As we found an increasing level of urinary $\beta-2$ microglobulin was proportionate to the degree of HIE $(P<0.001)$ (Table II), so, we can assign urinary $\beta-2$ microglobulin as a good predictor of outcome in perinatal asphyxia.

\section{Conclusion}

It was concluded from this study that raised urinary $\beta 2$ - microglobulin level may be related with HIE patients irrespective of clinical staging but serum creatinine and blood urea were found to be elevated only in stage III HIE patients. So estimation of urinary $\beta-2$ microglobulin level can be a good predictor in the diagnosis of renal dysfunction of asphyxiated babies. But to draw a conclusive evidence regarding relationship of urinary $\beta 2$ - microglobulin with advance stages of HIE in neonates with impaired renal function require further large scale study.

\section{References:}

1. Snyder EY, Cloherty JP. Perinatal asphyxia. In: Cloherty JP, Stark AR, editors Manual of neonatal care. $4^{\text {th }}$ ed. Philadelphia: Lippincott Raven Publishers, 1998: pp.515 32.

2. Perinatal Asphyxia. In: Gomella T.L. editor. Neonatology Management, Procedures, On-call problems, Diseases and Drugs. $6^{\text {th }}$ ed. USA: McGraw-Hill Companies. 2009: pp.624-636.

3. UNICEF, SOWC- United nation international children emergency fund, The state of world children 2009.

4. Bangladesh Bureau of Health Statistics. Dhaka: Bangladesh Bureau of Statistics, 2004: pp.9 13.

5. Black RE Dt. El, Global Regional and national cause of child mortality in2008; a systematic analysis. Lancet 2010; Jun 5: 375.

6. Gupta BD, Sharma P, Bagla J, Parakh M, Soni JP. Renal failure in asphyxiated neonates. Indian Pediatr 2005; 42: 92834.

7. Frank W, Julie $\mathrm{S}$, Corrado $\mathrm{M}$, Ian $\mathrm{H}$. Indices of renal tubular dysfunction in perinatal asphyxia. Arch Dis child 1997; 77: 57 -60.

8. Sarnat H.B, Sarnat M.S. Neonatal encephalopathy following fetal distress: A clinical and electroencephalographic study. Arch Neurol 1976; 33: 696-05.

9. Mohan PV, Pai PM. Renal insult in asphyxia neonatorum. Indian Pediatr 2000; 37:1102 6.

10. Fernandez F, Barrio V, Guzman J, Huertas MD, Zapatero M, de Miguel MD. $\beta$-2- microglobulin in the assessment of renal function in fullterm newborns following perinatal asphyxia. Am J Dis child 1989 ; 143: 617-20.

11. Tack ED, Perlman JM, Robson AM. Renal injury in sick newborn infants: a prospective evaluation 
utilizing $\beta$-2- microglobulin concentrations. Pediatrics 1988; 81:432-40.

12. Perlman JM, Tack ED, Martin T, Shackelford G, Amon $\mathrm{E}$. Acute systemic organ injury in term infants after asphyxia. Am J Dis Con 1989; 143: 617-20.

13. Chowdhury MAKA, Banu K, Rahman M. Birth asphyxia: a prospective study in Shishu
Hospital, Dhaka. Shishu Hosp J 1996; 12: 18-22.

14. Mangi ZA, Bouk GR, Junejo B, Junoje AL Shaikh $S$. Birth asphyxia relationship between hypoxic ischemic encephalopathy grading and development of acute renal failure in indoor term neonates at chandka medical college children hospital Larkana. Medical channel 2009; 15: 148152. 